\title{
Do free-range systems have potential to improve broiler welfare in the tropics?
}

\begin{abstract}
Much research has been conducted to mitigate the impact of conventional production systems on broilers welfare, but nearly all of these studies are based on the development of strategies to improve performance parameters in temperate regions, making it difficult to implement such approaches in tropical environments. Stocking density is one of the main housing variables that influences the birds' development. Optimal stocking density ranges from $25 \mathrm{~kg}$ to $40 \mathrm{~kg}$ liveweight per $\mathrm{m} 2$, with no less than $1 \mathrm{~m} 2$ of outdoor area per bird in some cases, for a minimum of $8 \mathrm{~h}$ of free-range access per day, according to welfare legislations in different jurisdictions worldwide. Several studies with commercial-line broiler chickens have shown that they are adapted to the environmental characteristics of tropical regions if the temperature is below $30^{\circ} \mathrm{C}$, relative humidity levels below $80 \%$ inside the housing and stocking density does not exceed 30 $\mathrm{kg} / \mathrm{m} 2$. Therefore, Latin America has great potential for the implementation of a free-range production system. The use of local resources, like forage plants for feed and natural materials with good thermal insulation properties for housing construction could be a good alternative to make this system feasible. $\mathrm{C} 4$ plants present in tropical ecosystems have a high rate of water-use efficiency in temperatures between $30-35^{\circ} \mathrm{C}$, which may increase the productivity of crops, fodder and pastures. Those plants are a good option to stimulate ranging in chickens, due to both their abilities as covering crop and fast-growing. The review concludes that outdoor access has the potential to improve broiler welfare in tropical regions, but it is still necessary to develop standards and regulations that ensure its proper functioning and, consequently, chicken welfare.
\end{abstract}

Keyword: Free-range; Housing; Stocking density; Broilers; Tropics; Environmental temperature; Welfare; Stress 